\title{
SISSY THAT TALK: a influência dos programas RuPaul Drag Race e Girls in the House no repertório linguístico de adolescentes e jovens adultos
}

\author{
Ludmila Mendes Ferreira \\ (UFJF) \\ https://orcid.org/0000-0002-8244-729X \\ Ana Cláudia Peters Salgado \\ (UFJF) \\ http://orcid.org/0000-0002-6881-3679 \\ Michele Cristina Ramos Gomes \\ (UFJF) \\ https://orcid.org/0000-0002-6878-4222
}

\section{RESUMO}

O primeiro objetivo deste estudo piloto é descrever a influência dos repertórios linguísticos dos reality show estadunidense RuPaul Drag Race, e da websérie brasileira do youtube Girls In The House, no repertório linguístico dos adolescentes, jovens e adultos na comunidade LGBTTI. Para o desenvolvimento deste estudo, foram considerados os aspectos ideológicos e identitários (BAUMAN, 2005; MOITA LOPES, 2002) que permeiam as expressões linguísticas desses grupos. Além disso, ao refletir sobre o atual contexto de superdiversidade (VERTOVEC, 2007), de globalização (KUMARAVADIVELU, 2006) e de contatos linguísticos-culturais muito mais intensos (RYMES, 2010), notamos que o repertório linguístico que nasce dentro de grupos LGBTTIs (e que é disseminado pelos programas) também reconfigura-se em grupos de adolescentes e jovens adultos que se identificam com os aspectos culturais e ideológicos de grupos LGBTTI, sem necessariamente fazerem parte dessa comunidade. Um segundo objetivo deste estudo piloto é descrever e analisar o repertório de adolescentes e jovens adultos, por meio de dados retirados do Facebook, especificamente de postagens do grupo secreto LDRV: Melodrama Era que, atualmente, possui mais de um milhão de membros. Posteriormente, foi realizado um estudo de caso a partir de entrevistas com membros do grupo a fim de descrever e analisar os usos linguísticos adotados pelos indivíduos e relacioná-los ao repertório dos programas de te- 
levisão e da comunidade LGBTTIs. Os resultados apontam que as séries funcionam como modelo de uso linguístico para os falantes que, assim, expressam suas ideologias e questões identitárias.

PALAVRAS-CHAVE: Superdiversidade, Repertório Linguístico, Ideologia, Identidade, LGBTTI.

\section{SISSY THAT TALK: the influence of the shows RuPaul Drag Race and Girls in the House in the linguistic repertoire of adolescents and young adults}

ABSTRACT

The first purpose of this pilot study is to describe the influence of the linguistic repertoires of the North-American reality show RuPaul Drag Race and of the Brazilian youtube webseries Girls In The House in the linguistic repertoire of adolescents and young adults in the LGBTTI community. For the development of this study, it was considered ideological and identity aspects (BAUMAN, 2005; MOITA LOPES, 2002) that permeate the linguistic expressions of these groups. Moreover, when we reflect on the current context of globalization (KUMARAVADIVELU, 2006) and on the more intense linguistic-cultural contacts (RYMES, 2010), we note that the linguistic repertoire that is born within LGBTTI groups (that are disseminated by the programs), is also reshaped in the groups of adolescents and young adults who identify with the cultural and ideological aspects of LGBTTI groups, without necessarily being part of that community. The second purpose of this pilot study is to describe and analyze the linguistic repertoire of adolescents and young adults, through data from Facebook, specifically from posts of the secret group LDRV: Melodrama Era, which currently has one million members. Subsequently, a case study was conducted from interviews with group members to describe and analyze the linguistic uses adopted by individuals to relate them to the repertoire of the television programs and the LGBTTI community. The results suggest that the series function as a model of linguistic use for speakers who, hence, express their ideologies and identity issues. 
KEYWORDS: Superdiversity, Linguistic Repertoire, Ideology, Identity, LGBTTI.

\section{Introdução}

No atual contexto globalizado ${ }^{1}$, caracterizado por uma diversidade dentro de uma diversidade, a que Steven Vertovec (2006) denomina superdiversidade, as mídias digitais tornaram-se um dos principais impulsores de identidades culturais/linguísticas. Nessa nova configuração, a cultura pop desempenha papel fundamental nas práticas cotidianas de letramentos digitais nas redes sociais. Assim, representando variadas vozes na internet, as diversas manifestações culturais, mais do que a promoção de conteúdo, são meios de construção e reconstrução de recursos linguísticos (DOVCHIN, PENNYCOOK \& SULTANA, 2018), configurando-se como elementos ímpares na construção linguística, social, ideológica e identitária de adolescentes e jovens adultos ligados à nova era digital.

Por essa razão, o objetivo deste estudo é descrever de que modo ocorrem as interações entre esses sujeitos bem como refletir sobre o impacto dos processos de (re)significação e transformação dos múltiplos discursos da cultura pop no seu repertório linguístico, na vida online.

No novo cenário da cultura digital, a rede social Facebook tem sido, possivelmente, o meio de interação online mais popular. Sobre esse aspecto, Sharman (2012) a caracteriza como um espaço transmodal: os usuários redefinem e transcendem o papel da língua em benefício de seus relacionamentos online, inovando não apenas no uso da língua local, mas também nos recursos linguísticos variados que perpassam textos multimodais de conteúdo local e global. Com efeito, recentemente, em virtude de sua ampla popularidade, de Bres (2015) e Bolander (2017) destacam seu papel protagonista nas práticas digitais cotidianas dos indivíduos na era globalizada.

Essa inovação e criatividade em mídia social é marcada por um uso da língua/linguagem imersa em formas de entretenimento popular que, por sua vez, abarca um universo de pessoas, lugares, línguas e culturas (DOVCHIN, PENNYCOOK \& SULTANA, 2018, p. 12). Desse modo, em comunidades do Facebook, afloram novos recursos linguísticos inspirados por programas associados à cultura pop, de forma que ela é, na era

${ }^{1}$ É importante ressaltar que o contexto de globalização a que se refere este estudo baseia-se nas definições de B. Kumaravadivelu (2013). 
digital, uma das principais fontes de recursos linguísticos e extralinguísticos para adolescentes e jovens adultos.

Nesse sentido, dois programas, no Brasil, vêm chamando a atenção no que diz respeito aos usos linguísticos nas redes sociais: o programa estadunidense RuPaul Drag Race ${ }^{2}$ e a websérie brasileira Girls In The House ${ }^{3}$.

O presente estudo pretende descrever de que maneira esses programas participam nos repertórios comunicativos (RYMES, 2014) dos sujeitos em seu cotidiano e nas práticas de letramentos digitais bem como refletir sobre esses usos e seu papel no que diz respeito às questões de ideologias e identidades (BAUMAN, 2005; MOITA LOPES, 2002).

\section{Aporte teórico}

$\mathrm{Na}$ contemporaneidade, a língua é entendida como um produto de atividades sociais e culturais (PENNYCOOK, 2010), de modo que a compreensão de rotinas comunicativas vai além de uma simples descrição da língua usada por indivíduos em situações de interação. Com efeito, a língua não é mais compreendida como simplesmente um código ou um sistema de regras e estruturas, mas, como afirma García (2014), uma série de ações e práticas sociais de falantes que interagem em uma complexa rede de relações cognitivas e sociais.

Por essa razão, Rymes $(2010,2014)$ propõe uma abordagem que pense as línguas como partes integrantes de um "repertório comunicativo" do sujeito, que consiste no conjunto de maneiras como os indivíduos usam a língua e outros modos de comunicação para interagirem nos múltiplos espaços dos quais fazem parte.

Para além de múltiplas línguas, dialetos e registros, o repertório de um indivíduo engloba gestos, vestimenta, postura, conhecimento de rotinas comunicativas, familiaridade com tipos de comida ou bebida, e referências da mídia e cultura popular, o que inclui frases, movimentos de dança e padrões de entonação que circulam via atores, músicos e outras celebridades (RYMES, 2012, 2014, p. 4, tradução nossa). ${ }^{4}$

\footnotetext{
${ }^{2}$ RuPaul Drag Race é um talent show estadunidense realizado pela produtora Word of Wonder apresentado pela Drag Queen RuPaul. Atualmente o programa é transmitido pelo canal VH1.

${ }^{3}$ Girls In The House é uma websérie brasileira feita no jogo "The Sims 4" e produzida pelo brasileiro Raony Philipes no youtube.

${ }^{4}$ One's repertoire can include multiple languages, dialects, \& registers, in the institutionally defined sense, but also gesture, dress, posture, and even knowledge of
} 
O repertório comunicativo, portanto, relaciona-se às diversas maneiras como os falantes manipulam e (re)significam os variados signos disponíveis em seu ambiente, para que se reconheçam como sujeitos agentes nas práticas comunicativas do cotidiano. Como as línguas consistem em "recursos móveis" apropriados pelo indivíduo para seu propósito comunicativo (BLOMMAERT, 2010 apud CANAGARAJAH, 2014), não parece apropriada uma abordagem que compreenda o repertório dos falantes como monolíngue.

Nesse sentido, neste artigo, adotamos como norte a perspectiva de práticas translíngues definida por Canagarajah (2014, p. 16) em duas noções: "primeiro, a comunicação transcende a língua individual e segundo, a comunicação transcende palavras e envolve diversos recursos semióticos e ecológicos". Assim, no contexto de diversidade linguística/cultural da contemporaneidade, entende-se que o "significado não surge a partir de um sistema comum gramatical ou de uma norma, mas surge por meio de práticas de negociação em situações locais" (CANAGARAJAH, 2014, p. 16, tradução nossa). Os sujeitos ressignificam e reconstroem seus recursos linguísticos em prol da interação, expondo, nesse movimento, suas intenções, identidades e disposições ideológicas.

Velghe (2015, p. 27, tradução nossa) destaca o papel da língua e das práticas de letramentos como meios de obtenção de uma voz, "o que permite ao indivíduo ser ouvido e compreendido". Ora, se entendermos as práticas linguísticas como um modo de obter voz no mundo, não poderemos dissociá-las de questões ligadas a ideologias e identidades. Sendo assim, a língua pode ser compreendida como um meio de construção identitária: "o que somos, nossas identidades sociais (...) são construídas por meio de nossas práticas discursivas com o outro" (MOITA LOPES, 2002, p. 32). Desse modo, ao contrário de serem fixas ou concluídas, as identidades consistem em um processo de constante (re)construção, consoante com o que postula Hall (1990, p. 220): “ao invés de pensarmos sobre identidade como um fato já concluído, (...) devemos pensar sobre identidade como uma "produção", que nunca está completa, que está sempre em processo".

Essa concepção vai ao encontro do que afirma Bauman (2005) quando destaca a fluidez do processo de formação da identidade pessoal

communicative routines, familiarity with types of food or drink, and mass media references including phrases, dance moves, and recognizable intonation patterns that circulate via actors, musicians, and other superstars (Rymes, 2012) 
por meio da alegoria do quebra-cabeça. De acordo com o autor, as identidades do sujeito são compostas por peças de um quebra-cabeça cuja figura é incompleta, faltando várias peças, sem um modelo ou imagem pronta para basear-se. Desse modo, o sujeito deve, por meio das experiências, buscar possíveis "peças" para a formação de uma "imagem final” que, por sua vez, não será definitiva ou imutável.

Ao considerar aspectos identitários e ideológicos (BAUMAN, 2005; MOITA LOPES, 2002) que permeiam os repertórios comunicativos (RYMES, 2014) dos indivíduos, o presente estudo propõe refletir acerca das manifestações identitárias em postagens do grupo "LDRV" no Facebook, bem como ponderar sobre o impacto da página na construção dessas identidades.

\section{Aspectos metodológicos}

Este estudo foi construído a partir de uma perspectiva de pesquisa qualitativa como a descrita por Denzin \& Lincoln (2006, p. 17): “abordagem naturalista, interpretativa, para o mundo, o que significa que seus pesquisadores estudam as coisas em seus cenários naturais, tentando entender, ou interpretar, os fenômenos em termos dos significados que as pessoas a eles conferem".

Nessa abordagem de pesquisa, que perpassa disciplinas, campos e temas, o pesquisador atua como observador e agente, descrevendo e interpretando momentos e significados do campo pesquisado. Segundo Denzin \& Lincoln (2006), como um bricouler que confecciona colchas, o pesquisador reúne informações, a partir das quais busca costurar possíveis tecidos finais. Considerando as expressões usadas pelos sujeitos nas postagens do Facebook, o papel influenciador dos referidos programas bem como o contexto social ideológico e as rotinas comunicativas desses falantes, este estudo pretende tecer uma possível colcha que descreva o repertório linguístico dos mesmos e as respectivas questões identitárias que se revelam.

O corpus coletado foi retirado da comunidade do Facebook Lana Del Rey Vevo ou LDRV. Trata-se de um grupo criado em 2013 por um brasileiro a fim de fundar um fórum humorístico para discutir música, cinema, arte e performances relacionadas ao mundo pop. No decorrer de seu processo de reconstrução na mídia social, o LDRV tornou-se um grupo fechado, ideologicamente ligado à causa LGBTTI $^{5}$.

${ }^{5}$ Lésbicas, gays, bissexuais, travestis, transexuais e intersexuais. 
Para interagir no fórum, os interessados devem solicitar participação e responder a um breve questionário sobre sua opinião política e ideológica. Caso as respostas ao questionário evidenciem compatibilidade ideológica com o grupo, o interessado é aceito pelo moderador do grupo e passa, se quiser, a ser agente nas postagens e comentários.

Em 2017, o fórum tornou-se um dos grupos mais populares do Facebook, atingindo a marca de um milhão de membros no Brasil. Em vista dessa crescente popularidade, considerando-se a faixa etária de seus membros - adolescentes e jovens adultos entre 15 e 35 anos - e a estreita ligação com a cultura pop, o LDRV: MELODRAMA ERA ${ }^{6}$ foi o espaço digital escolhido no Facebook para a seleção de dados desta pesquisa.

No início de 2017, solicitamos a participação no grupo e, posteriormente à aceitação, buscamos nas postagens uma lista de expressões e recursos linguísticos relacionadas aos programas RuPaul Drag Race e Girls In The House. Em seguida, selecionamos dessa lista duas expressões de cada programa, de uso mais corrente, e destacamos trechos relevantes das postagens. Buscamos com essa seleção propor uma reflexão sobre os variados usos dessas expressões assim como sobre seu impacto na construção ideológica e identitária dos falantes.

Posteriormente, realizamos entrevistas semiestruturadas com membros ativos do LDRV, para entender a relação desses sujeitos com a comunidade e seu papel nos repertórios comunicativos (RYMES, 2014).

\section{Reflexão sobre os dados}

Na nova configuração global, adolescentes e jovens adultos estão engajados com estilos musicais, filmes, séries, jogos e outras variadas formas de cultura popular. Estas, além de promoverem conteúdo para as interações no cotidiano, tornam-se também vozes e recursos linguísticos (DOVCHIN, PENNYCOOK \& SULTANA, 2018). Os jovens assimilam e ressignificam as múltiplas vozes da cultura pop e, ao fazê-lo, ganham acesso a uma diversificada gama de línguas, ideias e maneiras de articularem o mundo. Nesse sentido, Dovchin, Pennycook \& Sultana (2018, p.2, tradução nossa) destacam que "a criatividade linguística, portanto, envol-

${ }^{6} \mathrm{O}$ grupo Lana Del Rey Vevo costuma ter seu nome modificado de acordo com as tendências do mundo pop e da internet. No momento da pesquisa o grupo era intitulado: LDRV: MELODRAMA ERA. 
ve vozes, sons, imagens e frases retiradas de variadas formas culturais, de músicas a cenas de filmes populares, de informações sobre celebridades do esporte a detalhes sobre tecnologias".

No cenário da cultura digital, no Facebook, espaço marcado por essa criatividade linguística, "os usuários retextualizam e relocalizam diversos signos e recursos linguísticos disponíveis para assim criarem suas próprias versões de letramentos digitais" (THORNE, 2013, apud DOVCHIN, PENNYCOOK \& SULTANA, 2018, p. 17). Nesse sentido, partindo de uma perspectiva de repertórios comunicativos (RYMES, 2010) que perpassam práticas translíngues (CANAGARAJAH, 2014) envolvidas em diversas questões ligadas a aspectos de ideologias e identidades (MOITA LOPES, 2005; BAUMAN, 2002), este tópico propõe uma reflexão acerca dos usos no Lana Del Rey Vevo: Melodrama Era.

Para isso, em um primeiro momento, serão apresentadas as postagens coletadas na comunidade do Facebook seguidas de reflexões acerca das expressões utilizadas. Em um segundo momento, serão abordadas as entrevistas com membros ativos do Lana Del Rey Vevo a fim de elucidar questões envolvidas em suas práticas digitais. Por fim, serão propostas reflexões sobre o impacto dos diversos usos apresentados no repertório comunicativo desses falantes, bem como o papel desses usos na formação da identidade do sujeito contemporâneo.

\subsection{RuPaul Drag Race}

Talent show estadunidense estreado em 2009 pelo canal Logo TV e apresentado pela drag queen RuPaul Andre Charles, o Rupaul Drag Race chegou ao Brasil em 2013, transmitido pelo canal fechado VH1 Brasil, tornando-se extremamente popular nos últimos três anos, especialmente entre adolescentes e jovens adultos ligados ao discurso e às disposições ideológicas do grupo LGBTTI. Atualmente, em sua décima temporada, ele se tornou um espaço de criação, divulgação e ressignificação de expressões, memes, gifs e variados recursos linguísticos e semióticos que circulam pelas diversas mídias sociais.

$\mathrm{Na}$ tabela abaixo, foram destacados alguns usos da expressão "shade", termo originalmente utilizado em grupos de drag queens dos Estados Unidos $^{7}$, que foi popularizado pelo programa Rupaul Drag Race e res-

${ }^{7}$ Informação retirada do documentário Paris Is Burning. 
significado nas redes sociais. Inicialmente a expressão era utilizada para referir-se a uma drag que estava sendo maliciosa com a outra, criticando de forma indireta sua companheira. Contudo, como veremos nos exemplos a seguir, essa expressão foi reinterpretada e adaptada ao contexto e às interações cotidianas de jovens que participam de práticas digitais no grupo LDRV.

Tabela 1 - "Shade"

\begin{tabular}{|c|c|}
\hline Expressào & Significado \\
\hline "Shade" & Indireta maldosa, ironia \\
\hline Membro A para LDRV: MELODRAMA ERA \\
10 de abril
\end{tabular}

Nesses exemplos, são destacados variados usos da expressão "shade" aplicados a diferentes contextos e situações comunicativas. Na postagem do membro A, por exemplo, o termo é utilizado para relatar e compartilhar com outros uma experiência familiar do sujeito, referindo-se a um hábito de um membro da família. Já na publicação dos membros B e C, essa expressão é usada para comentar eventos e polêmicas relacionados à cultura pop. Nesses contextos de uso, percebe-se que a expressão em tela, além de ser incorporada de maneira natural e fluida à rotina comunicativa dos falantes, é adaptada a aspectos cotidianos ligados às múltiplas formas de relacionamentos online, transmitindo posicionamento político ideológico. 
Na tabela 2 a seguir, apresentamos e discutimos as expressões "Shantay you stay" e "Sashay away", que passaram por um processo similar ao do termo "shade". Ambas foram popularizadas pelo programa RuPaul Drag Race quando, no fim de cada episódio, no desafio final "Lypsinc for your life" -, a apresentadora declarava "shantay you stay" para vencedora e "sashay away" para a eliminada. Da mesma forma que o termo da tabela 1, as expressões foram ressignificadas pelos falantes e adaptadas ao seu contexto, significando, respectivamente, aprovação e desaprovação.

\begin{tabular}{|c|c|}
\hline Expressão & Significado \\
\hline "Shantay you stay/Sashay away" & $\begin{array}{c}\text { Shantay you stay: Permanência, aprovação } \\
\text { Sashay away: Dispensar, reprovar }\end{array}$ \\
\hline \multicolumn{2}{|c|}{$\begin{array}{l}\text { Membro G para LDRV: MELODRAMA ERA } \\
\qquad 12 \text { de julho } \\
\text { all the Conselheiros desse meu, seu e nosso LDRV [...] } \\
\text { a mãe gosta da minha namorada mas impõe algumas regras, diz sashar } \\
\text { mas trata ela com muita shantay you stay sim senhores. }\end{array}$} \\
\hline \multicolumn{2}{|c|}{$\begin{array}{l}\text { Membro I para LDRV: MELODRAMA ERA } \\
\qquad 17 \text { de maio } \\
\text { Claramente o fora temer vai cair graças ao sashav away da Mama Ru } \\
\text { ESSE MOMENTO É NOSSOOOO, AMEM RUPAULA }\end{array}$} \\
\hline
\end{tabular}

Tabela 2 - "Shantay you stay / Sashay away" 


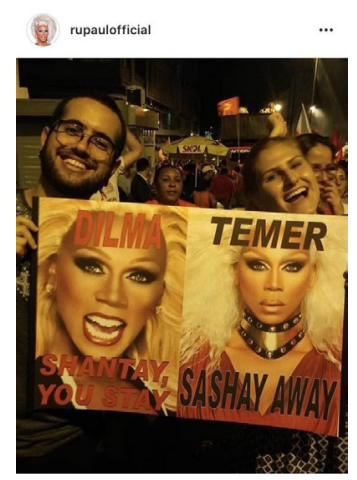

Figura 1

Na postagem do membro $\mathrm{G}$, ele usa as expressões referindo-se à sua vida pessoal: relata sua insatisfação com o comportamento de sua família em relação à sua companheira. Destaca-se, também, a maneira como esse sujeito comunica-se por meio de uma translinguagem (CANAGARAJAH, 2011a, p. 401 apud GARCIA, 2014, p. 21 tradução nossa), que é definida como "a habilidade de falantes multilíngues trocarem entre línguas, tratando as diversas línguas que formam seu repertório como um sistema integrado". Desse modo, ao utilizar signos linguísticos associados ao Inglês e ao Português - "Calling all the Conselheiros" -, o membro G está translinguando. Essa translinguagem bem como o uso das expressões "Shantay you stay" e "Sashay away" formam o repertório comunicativo individual e compartilhado do sujeito. Além disso, a publicação também representa a força ideológica e identitária que envolve os usos e os recursos selecionados pelo sujeito G: ao escrever "meu, seu e nosso LDRV", ele expressa seu sentimento de pertencimento ao grupo. Esse desejo de pertencer é destacado por Bauman (2005) como um impulsor da busca por uma identidade.

A publicação do membro "I", por sua vez, destaca-se no que diz respeito a questões relacionadas a ideologias políticas, tanto dos sujeitos na fotografia, quanto do responsável pelo post. Na imagem 1, há um cartaz referente às manifestações de 2017, em que as expressões "Sashay you stay" e "Shantay away" são utilizadas para demarcar um posicionamento político, que está além da escolha de um candidato ou outro, mas que representa importantes posições ideológicas. As expressões nessa 
imagem carregam uma voz, uma representação de um grupo ideológico, em que são evidenciadas características identitárias. Nesse caso particular, o uso dos termos associados a cultura drag em seu repertório comunicativo possibilita pensar que esse grupo defende um posicionamento político ideológico associado às questões LGBTTI.

\subsection{Girls in the house}

Criada e produzida pelo brasileiro Raony Phillips para seu canal do Youtube - RaoTV -, Girls In The House é uma websérie animada brasileira, que teve início em 2014 e ganhou popularidade em 2016, quando Raony publicou "Disk Duny: Kim Expõe Taylor" - um spin off ${ }^{8}$ da websérie -, em que, parodiando o programa popular Keeping up with the Kardashians, explora polêmicas envolvendo estrelas do mundo pop.

Ao tratar as notícias e tendências do mundo pop internacional de maneira humorística na visão de um brasileiro, o RaoTV transformou-se em um dos mais populares canais do Youtube, estendendo seu domínio a outras mídias sociais. Através de sua série, Raony manipula e ressignifica as variadas vozes e discursos da corrente cultura pop e, ao fazê-lo, gera novas vozes e recursos linguísticos, os quais, por sua vez, serão novamente manipulados e remodelados, em um fluido processo de construções linguísticas. Essas (re)construções, por fim, integram os variados elementos que compõem o repertório comunicativo dos novos falantes das redes sociais.

Na tabela a seguir, é apresentada a expressão "Eu vou expor ela", da websérie "Disk Duny: Kim expõe Taylor", que, em 2016, popularizou-se nas redes sociais em forma de memes, como se vê na imagem 2, e, atualmente, é usada quando o falante pretende expor uma situação ou um ocorrido na internet.

\footnotetext{
8 "A book, film, or television series derived from a similar successful book, film, or television series" (Um livro, um filme, ou uma série televisiva derivada de um livro, filme ou série televisiva similar de sucesso. Tradução nossa). Disponível em: https:// www.collinsdictionary.com/pt/dictionary/english/spin-off (Acesso em: 15/09/2018)
} 
Tabela 3 - "Eu vou expor ela"

\begin{tabular}{|c|c|}
\hline Expressào & Significado \\
\hline "Eu vou expor ela" & $\begin{array}{l}\text { Expor alguém ou alguma situação nas redes } \\
\text { sociais }\end{array}$ \\
\hline \multicolumn{2}{|c|}{$\begin{array}{l}\text { Membro D para LDRV: MELODRAMA ERA } \\
\qquad 28 \text { de julho } \\
\text { Eu vou expor ela na internet } \\
\text { bebe e "vira" gay e existe meu amigo que bebe e }\end{array}$} \\
\hline \multicolumn{2}{|c|}{$\begin{array}{l}\text { Membro E para LDRV: MELODRAMA ERA } \\
\text { 1 de fevereiro - Maceió, Alagoas } \\
\text { EU VOU EXPOR ELA: } \\
\text { Tem coisa mais retrógrada do que um viado metido a opressor? Tem coisa mais vergonhosa. } \\
\text { ridicula e abominável que isso? Amor, saiba que quando uma gay ganha TODAS NóS } \\
\text { SAIMOS GANHANDO também. }\end{array}$} \\
\hline $\begin{array}{l}\text { Membrc } \\
\text { Eu vou expor ela sim pq } \\
\text { supermerca }\end{array}$ & $\begin{array}{l}\text { V: MELODRAMA ERA } \\
\text { maio } \\
\text { das Mães }<3 \\
\text { heganio } \\
\text { maravilhosa e gonga com a minha cara no } \\
\text { agressiva no xingamento... }\end{array}$ \\
\hline
\end{tabular}

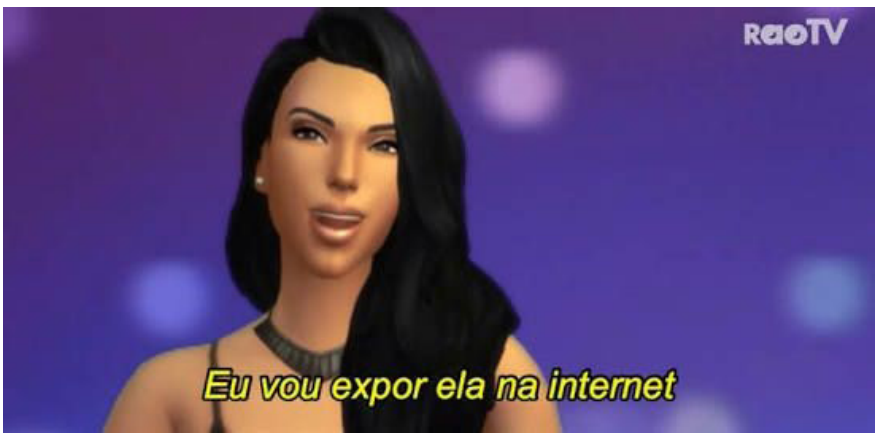

Figura 2 
Devido ao grande número de publicações e compartilhamentos, a expressão foi incorporada ao cotidiano linguístico dos sujeitos nas redes sociais. Os exemplos retirados do Lana del Rey Vevo ilustram de que modo os falantes adaptaram e modelaram essa expressão de acordo com seus repertórios e necessidades comunicativas. Nota-se pelas publicações que, mais do que modificar os sentidos, há possibilidades de modificar ou expandir o contexto de uso das expressões.

Originalmente, o significado da frase era relacionado à desaprovação de uma situação ou da conduta de um indivíduo. Posteriormente, como notamos na publicação do membro $\mathrm{F}$, a expressão passa também a destacar uma situação de admiração, em que se deseja valorizar algo ou alguém por meio de uma exposição de características pessoais ou detalhes de sua vida.

Na tabela a seguir, são apresentados exemplos de uso de outra expressão que também foi popularizada nas redes sociais, em especial no Facebook: "Caralho Blue Ivy". Assim como a frase analisada anteriormente, essa expressão também ficou conhecida a partir de um episódio do spin off "Disk Duny", o "Cativeiro da Beyónce".

Tabela 4 - "Caralho Blue Ivy"

\begin{tabular}{|c|c|}
\hline Expressão & Significado \\
\hline "Caralho Blue Ivy" & $\begin{array}{l}\text { Pessoa desprovida de inteligência, sonsa, } \\
\text { distraída, desligada. }\end{array}$ \\
\hline \multicolumn{2}{|c|}{$\begin{array}{l}\text { Membro J para LDRV: MELODRAMA ERA } \\
\quad 3 \text { de outubro às } 21: 14 \text {. } \\
\text { adas, vocês também vão pra aula, "entendem" a matéria e quando } \\
\text { fazer exercícios em casa ficam "CARALHO BLUE IVY TU E } \\
\text { MTO BURRA MESMO"? }\end{array}$} \\
\hline \multicolumn{2}{|c|}{$\begin{array}{l}\text { Membro K para LDRV: MELODRAMA ERA } \\
\text { [EU VOU EXPOR ELA NA INTERNET] } \\
\text { ELA ESTA AMIGA TBM DORME E ACHAM QUE } \\
\text { CALLING ALL THE MANASS!!! SUA AMIG } \\
\text { A fodida da nossa amiga dormiu e não avisou ninguém que tinha chego em casa, a } \\
\text { familia não procurou ela no quarto CARALHO BLUE IVY e entrou em pânico pq } \\
\text { já eram 21h!!! }\end{array}$} \\
\hline
\end{tabular}


corporada pelos membros da comunidade do Facebook e, ao utilizá-la como recurso para interação no grupo, os membros marcam um posicionamento ideológico, revelando, por meio de seus repertórios comunicativos, suas identidades e preferências.

Mediante os dados apresentados, podemos perceber que essas expressões não só integram, constroem e reconstroem o repertório comunicativo dos falantes, mas também são transformadas, modeladas e reconfiguradas pelo repertório individual do sujeito em um processo de reciprocidade. Em outras palavras, com a assimilação de elementos de repertórios comunicativos presentes nos programas de TV citados, o repertório comunicativo do sujeito, por sua vez, reconfigura e modifica essas expressões.

Nos dados destacados, os sujeitos compartilham ideologias e posicionamentos políticos relacionados à comunidade LGBTTI e buscam integrar aos seus repertórios elementos que representem seu posicionamento. Visto que a cultura pop tem uma forte conexão com o grupo LGBTTI - especialmente no que diz respeito à sua construção identitária - reinterpretar, ressignificar e reconstruir as ideias, imagens, papéis, vozes e discursos do universo pop é - usando a terminologia de Moita Lopes (2002) e Bauman (2005) - uma estratégia de buscar "peças" que possam completar uma identidade fragmentada. Em suma, é possível afirmar que a reflexão sobre os dados revela que "à medida que nosso repertório muda gradualmente para se sobrepor ao de outros (incluindo maneiras comuns de cumprimentar, brincar, gesticular ou se vestir, por exemplo), desenvolvemos um senso de pertencimento compartilhado" (RYMES, 2014, p. 16).

Os dados revelam que, na busca por identificação e por uma voz representativa, os jovens e adolescentes associados à cultura pop e à era digital procuram em programas de televisão influentes uma forma de (re) modelar seu repertório linguístico para que haja agentividade e representação de um sujeito situado.

No tópico a seguir, destacamos trechos de entrevistas realizadas com membros do grupo Lana del Rey Vevo, do Facebook, nas quais evidenciamos a importância das expressões analisadas para a identidade e rotina comunicativa de alguns sujeitos. 


\subsection{OS PARTICIPANTES DO LDRV}

Para melhor compreender as perspectivas desses jovens e adolescentes em relação às expressões ressaltadas no tópico anterior, foram realizadas entrevistas semiestruturadas nas quais destacamos, na construção identitária e ideológica desses sujeitos, o papel das expressões bem como a relação delas com a vida online e off-line dos respectivos sujeitos. No trecho a seguir, entrevistamos uma aluna de enfermagem, negra de 28 anos, que se identifica como mulher e bissexual:

$[\ldots]$

P: O que que você sente que faz você pensar que é melhor postar uma coisa lá (no grupo LDRV) do que no seu próprio perfil do Facebook?

A: A....eu me sinto à vontade, eu me sinto livre, eu sinto que não vou ser julgada.

P: Sobre as expressões que você usa nesse grupo, têm alguma intenção, algum propósito o uso das coisas que você escreve lá dentro?

A: A, tem o propósito de divertir as pessoas. Eu amo essas gírias, é um hinooooo ((risos)). E assim, todo lugar que eu vou e falo essas gírias todo mundo pega.

P: E o que você escreve no Lana (LDRV) você fala no seu cotidiano?

A: Falo!

P: E de onde vêm essas expressões que você usa?

A: Dos bordões das gays, né!

P: Entendi ((risos)). Mas assim, de onde você pega, usa...

A: Ah, eu falo muito " eu amoooooh", "teve irene", "embuste", ... "tô chateada com você", com a voz da personagem do GITH, ((risos)), "caralho, blue ivy tu é muito burra", "eu vou expor ela" esses são do Girls In The House. E... falo, também que "hinoooooo", "berro", "que sapão da porra"... esses eu peguei no Lana. É muita coisa! Agora, Girls 
In The House, foi aí que eu comecei meus bordões.

P: Que você acha que essas expressões têm de importante no que diz respeito a sua identidade?

A: Acho que é a maneira deu me expressar, eu me expresso assim na frente de qualquer pessoa!

P: E você acha que isso mostra quem você é, e nas coisas em que acredita?
A: Sim, sim.
P: Por que?

A: Porque não é uma coisa comum, eu me diferencio.

P: Entendi.

A: Não me vejo como uma pessoa comum.

P: Você acha que a língua é uma maneira de expressar o que somos?

A: Eu acho que é uma maneira de mostrar que eles (comunidade LGBTTI) são diferentes, que eles não são assim, iguais a todo mundo, que eles têm o seu brilho, assim, o seu up, o seu diferencial.

O primeiro aspecto a se destacar é a perspectiva da jovem acerca do grupo LDRV no Facebook. Para ela, mais do que um espaço de interação digital, a comunidade é um espaço de liberdade e representação livre de julgamentos. Isso também evidencia que, mais do que participar na construção de sua identidade linguística, as expressões são uma maneira de diferenciar-se no mundo, o que torna seu repertório individual, único em que ela é agente: "A: Porque não é uma coisa comum, eu me diferencio (...) Não me vejo como uma pessoa comum".

Outro aspecto que deve ser realçado são os usos linguísticos na vida online e off-line da entrevistada, que afirma utilizar as expressões em seu cotidiano fora das redes sociais: "A: $\mathrm{E}$ assim, todo lugar que eu vou $\mathrm{e}$ falo essas gírias todo mundo pega. (...) / P: E o que você escreve no Lana (LDRV) você fala no seu cotidiano? / A: Falo!".

Isso remete a Dovchin, Pennycook \& Sultana (2018, p. 16), segun- 
do os quais, na mais recente fase da globalização, "não faz mais sentido enfatizar a 'virtualidade' de uma realidade em relação a outra, visto que estar online é muito real, e estar off-line é permeado pelo online".

No fragmento a seguir, entrevistamos o sujeito B - um estudante de física, negro, de 21 anos, que se identifica como homem e homossexual - e o sujeito $\mathrm{C}$ - um estudante de letras, branco, de 19 anos, que se identifica como homem, homossexual e drag queen:

$[\ldots]$

L: Você acha que lá é um espaço para quê? Qual é a característica desse espaço?

$\mathrm{C}$ : Eu acho que é muito fácil visualizar isso porque quase todo mundo que posta no LDRV não posta as coisas que posta no próprio perfil do Facebook. Então o grupo é meio que um espaço para você poder compartilhar conteúdo específico, que você sabe que vai ter outras pessoas interessadas, se você colocar no seu feed do Facebook e, geralmente, as pessoas têm família ou tipo amigos que não fazem parte desse grupo, fazem parte de outros grupos, tem muitas coisas que o LDRV te dá liberdade de fazer, você tem liberdade de falar sobre determinados assuntos no grupo.

L: Entendi. E qual é esse grupo, público que você acha que tem no LDRV?

C: Majoritariamente LGBT, não tem só LGBT, mas tipo, 90\%.

B: Deveria ter só LGBT.

C: É deveria.

L: Vocês acham que deveriam ter só LGBTs?

C: Sim, porque o grupo não LGBT que faz parte do Lana, assim, surge as vezes e começa dá a louca nos heteros, e eles ficam tipo. Aí se fosse só LGBT, a liberdade que tem, seria, tipo, bem maior!

L: E as expressões e a linguagem que você usa nesse grupo têm alguma intenção, propósito? 
C: Eu acho que é mais o entendimento, é o vocabulário específico de um grupo específico. Então isso passa uma identidade, quando um grupo tem um vocabulário que só ele fala, isso cria um sentimento de pertencimento nas pessoas desse grupo. Então, muita gente faz isso inconscientemente, acaba reproduzindo porque acha legal, mas inconscientemente isso tá presente, esse sentimento de pertencimento, tipo, eu vou falar assim, pessoas que são iguais a mim vão entender o que eu tô falando.

$[\ldots]$

L: A minha outra pergunta é se você acha que pessoas que não estão no LDRV compreendem a sua linguagem e seu uso?

B: Hum... Num primeiro momento não, mas com o tempo elas vão compreendendo.

L: O que você acha que ajuda a compreender?

B: Eu acho que é exposição mesmo, quanto mais eu uso, mas elas vão vendo o contexto.

L: Essa linguagem é de algum grupo específico?

B: Eu acho que é muito do meio LGBT que vai criando sua identidade a partir disso.

$[\ldots]$

L: E quais expressões você costuma usar, no LDRV ou na vida?

C: Nossa! Têm muitas! E “que hinoo", “que sapão” (risos), sapão é tipo muito, eu uso na vida real inclusive, no dia-a-dia uso direto é uma das coisas que eu mais falo. "Flop", também, "Shade", esse é mais do RPDR, tem vocabulário mais Ru Paul mas que é integrado a cultura LGBT de uma maneira geral. Não é específico do grupo da internet, mas é usado bastante. Têm séries menores também, tipo Gitls In The House, mas foi Ru Paul que trouxe uma enxurrada de expressões.

L: Entendi. E de onde que você tira, então essas expressões, assim de onde pega elas? 
$\mathrm{C}$ : Eu acho que é uma coisa mais orgânica, sabe?! Quando uma gíria ela é estabelecida na sociedade, em um grupo linguístico, não tem uma reunião, a gente vai usar essa e essa palavra, e uma coisa que...

B: A, as vezes a gente reúne sim! ((risos)).

L: Qual a importância que vocês vêm, como membros do grupo, nessas expressões, o que ela representa para vocês?

B: Liberdade de expressão! Eu poder me expressar do jeito que eu quero.

C: Sim! Também tem identificação.

B: É!

C: E você saber que se você falar de tal jeito as pessoas que se identificam com você, que se identificam com as mesmas coisas que você vai entender. Isso já é meio caminho andado, só de você chegar e falar alguma coisa, as pessoas já, tipo, chamam atenção pra aquilo, e mesmo ninguém se conhecendo, você consegue formar um grupo, por causa de uma expressão que você usou. Isso acontece muito!

As respostas dos entrevistados evidenciam que o emprego dos termos apresentados no cotidiano comunicativo dos falantes também se tornou uma maneira de limitar quem está nesses grupos e quem não está: "L: Entendi. E qual é esse grupo, público que você acha que tem no LDRV? / C: Majoritariamente LGBT, não tem só LGBT, mas tipo, 90\%. / B: Deveria ter só LGBT. / C: É deveria".

Essa passagem remete a Dovchin, Pennycook \& Sultana (2018, p. 2 , tradução nossa), de acordo com os quais, "à medida que os falantes comunicam-se, perpassando vários grupos sociais [...] eles definem com o tempo os usos da linguagem subcultural, que mostram quem está dentro, quem está fora, quem sabe mexer com a linguagem e a imagem dessa maneira e quem não sabe".

Os usos destacados nas postagens do Lana Del Rey Vevo ilustram a maneira como os recursos linguísticos e semióticos são utilizados para definir quem pode participar do grupo, podendo, dessa forma, entender as interações e agir por meio delas. Como o entrevistado afirma, em um primeiro momento, se o indivíduo não está familiarizado com as rotinas comunicativas do grupo, não é possível compreender completamente o 
que é dito: "L: A minha outra pergunta é se você acha que pessoas que não estão no LDRV compreendem a sua linguagem e seu uso? / B: Hum... Num primeiro momento não, mas com o tempo elas vão compreendendo".

Nas entrevistas, destaca-se o papel dessas expressões como elementos de construção identitária, remetendo ao que Bauman (2005, p. 22) denomina como "modernidade líquida", que é marcada por identidades fragmentadas, e estas, por sua vez, também são "liquidas", frágeis, instáveis, fluidas e inconclusivas, em uma condição eternamente provisória. Nesse sentido, segundo o autor, a aspiração a uma identidade surge do desejo de segurança. Logo, no contexto atual de mudanças sociais e de avanços em tecnologia digital - percepção de redução de distância, tempo e espaço -, o sujeito busca algo para se identificar, um lugar para pertencer, criando um sentimento de unidade.

$\mathrm{Na}$ entrevista, quando o sujeito $\mathrm{C}$ afirma que, "mesmo ninguém se conhecendo, você consegue formar um grupo, por causa de uma expressão que você usou", notamos o impacto do uso das expressões com o desejo de pertencer a um grupo que irá formar sua identidade, bem como de afastar-se do isolamento.

\section{Considerações para fins de conclusão do presente artigo}

A difusão das redes sociais e da cultura digital possibilitou, na contemporaneidade, um ambiente de divulgação e de novas rotinas e hábitos comunicativos. O presente estudo buscou, a partir desse contexto, tecer algumas relações entre os programas pops - RuPaul Drag Race e Girls In The House - e elementos do repertório linguístico de jovens e adolescentes da era digital, em postagens de um grupo secreto do Facebook - Lana Del Rey Vevo.

A partir da reflexão sobre os dados, é possível afirmar que, de fato, é contestável a noção de que a língua é apenas um sistema e que no Brasil vive-se uma realidade monolíngue. Nas interações apresentadas, o modo como a comunicação transcende a língua e torna-se uma forma de agir no mundo demonstra que a língua é um elemento de um vasto e complexo repertório comunicativo em que o sujeito tem papel de agente.

Ademais, os recorrentes usos de expressões e itens lexicais associados a línguas diferentes em conjunto, nas postagens, tornam possível confirmar que o limite entre o que se entende como língua não é tão claro, ou fixo. Ou seja, isso permite-nos dizer que vivemos em uma realidade 
caracterizada por uma translinguagem (CANAGARAJAH, 2014).

Para além disso, os achados da pesquisa (postagens e entrevistas) apontam que as séries RuPaul Drag Race e Girls In The House funcionam como modelos de uso linguístico para os falantes associados à cultura pop e às disposições ideológicas de grupos LGBTTIs. Além disso, por meio desses termos, adolescentes e jovens adultos constroem e reconstroem seus repertórios comunicativos (RYMES, 2010), por meio dos quais expressam suas vozes, posicionamentos políticos, ideologias e questões identitárias.

\section{REFERÊNCIAS}

BAUMAN, Zygmunt. Identidade. Rio de Janeiro, Zahar, 2005

BETSY, Rymes. Communicating Beyond Language: Everyday Encouters with Diversity. New York, Routledge, 2014.

BETSY, R. Communicative Repertoire. In: . The Routledge Companion to English Studies. New York, Routledge, 2014. Cap. 19, p. 287-301.

BOLANDER, B. Language and identity on Facebook, In: Language, education and technology: Encyclopedia of language and education, Springer International Publishing, 2017, p. 1-13.

CANAGARAJAH, Suresh. Translingual Practice: Global Englishes and Cosmopolitan Relations. London and New York, Routledge, 2013.

DE BRES, J. (). Introduction: Language policies on social network sites, In: Language Policy, 2015, 14(4), p. 309-314.

DENZIN K. Norman; LINCOLN S. Yvonna. O Planejamento da Pesquisa Qualitativa: Teorias e Abordagens. Porto Alegre, Artmed, 2006.

DOVCHIN, Sender, PENNYCOOK, Alastair \& SULTANA, Shaila. Popular Culture, Voice and Linguistic Diversity: Young Adults On- and Offline. NSW, Australia, Palgrave Mcmillian, 2018.

GARCÍA, Ofelia \& WEI, Li. Translanguaging: Language, Biligualism and Education. London and New York, Palgrave Macmillan, 2014.

MILLS, Kathy et. al. Handbook of Writing, Literacies, and Education in Digital Cultures. New York, Routledge, 2018.

MOITA LOPES. L. Paulo. Identidades Fragmentadas: A construção discursiva de raça, gênero e sexualidade em sala de aula. Campinas, SP, Mercado de Letras, 2002. 
PENNYCOOK, A. Popular cultures, popular languages and global identities. In: The handbook of language and globalization, Oxford: Blackwell, 2010, p. 592- 607.

SHARMA, B. K. Beyond social networking: Performing global Englishes in facebook by college youth in Nepal, In: . Journal of Sociolinguistics, 2012, 16(4), p. 483-509.

VELGHE, F. "Hallo hoe gaandit, wat maak jy?": Phatic communication, the mobile phone and coping strategies in a South African contexto, In: . Multilingual Margins: A Journal of Multilingualism From the Periphery, 2(1), 2015, p. $10-31$.

VERTOVEC, Steven. The Emergence of Super-Diversity in: Britain. Centre on Migration, Policy and Society. Working paper n. 25, University of Oxford, 2006.

Recebido em: 31/09/2018

Aceito em: 21/03/2019 